\title{
Assessing risk through Composite FMEA with pairwise matrix and Markov chains
}

\begin{tabular}{|r|l|}
\hline Journal: & International Journal of Quality \& Reliability Management \\
\hline Manuscript ID & IJQRM-04-2017-0080.R1 \\
\hline Manuscript Type: & Quality Paper \\
\hline Keywords: & FMEA, Risk analysis, Markov Chain, Pairwise comparison \\
\hline Abstract: & \\
\hline \multicolumn{2}{|l}{} \\
\hline
\end{tabular}

SCHOLARONE ${ }^{\mathrm{m}}$

Manuscripts 


\section{Abstract}

Purpose: FMEA is an analysis technique for identifying and eliminating known and/or potential failures and problems from products, processes, systems. Notwithstanding its diffusion, traditional FMEA has several limitations. Lately, scientific research has been focused on improving said limitations, yet the process is still ongoing. The present paper aims at supporting developments in this area.

Methodology: The paper improves the conventional FMEA by using the method of Pairwise Comparison to establish the relative importance of the input factors in RPN calculation, and Markov Chains to calculate risk distributions in the long term.

Findings: The functioning and usefulness of the proposed methodology is demonstrated through an application to the construction industry, one of the world's biggest industrial sectors, dogged by a high rate of work-related injuries and casualties.

Originality/Value: Having demonstrated the applicability of the novel methodology to a real domain, the paper contributes to the process of overcoming traditional FMEA limitations.

\section{Keywords: FMEA, Pairwise comparison, Markov Chain, Risk analysis}

\section{Introduction}

Although companies, project managers and risk engineers have defined several methodologies and tools supporting the assessment of project or system risks and to increase systems reliability and safety, it is very difficult to find an encompassing tool or methodology that can guarantee complete safety, reliability and a risk-free project or system.

According to the International Labour Organization (www.ilo.org), construction industry is one of the world's biggest industrial sectors, including demolition and maintenance industries. In many developing countries, construction industry is among the fastest growing areas of the labour market, continuing to provide a traditional entry point for labourers.

In this industrial context, scientific research attempts to come up with an improved version of Failure Mode and Effect Analysis (FMEA) that could be suitable to the construction domain requirements for a sound and encompassing assessment of risks, by eliminating or at least reducing the shortcomings of traditional FMEA approach. Furthermore the aim of the present work is to develop a new risk assessment methodology with the following merits: (1) Ease of understanding, (2) Ease of use from both managers and engineers, (3) Considering a wider range of criticality factors, (4) Avoiding or at least reducing the conventional FMEA shortcomings, (5) Considering the mutual influence between failure modes, (6) Providing a good level of flexibility and customization for the user.

Therefore, an integration between the conventional Failure Mode and Effective Analysis (FMEA), the method of Pairwise Comparison and the Markov Chain, has been used to create a Composite FMEA (COMPFMEA).

The proposed methodology not only allows users to create their own criticality factors that might affect their projects/processes, but also provides them with a guideline on the evaluation criteria. Moreover, it also takes into consideration the effect of interdependence between different failures. In order to show the application of the proposed methodology, a case study in the construction sector is discussed, allowing users to figure out the potential of the proposed methodology, as well as providing practical guidelines on how to apply COMP-FMEA to a real case.

The remainder of paper is organized as follows. Section 2 presents a review of the recent literature state of art. Section 3 presents the research objectives and framework, while the Case Study illustrating the model application is discussed in Section 4. Finally, Section 5 concludes the paper, drawing final remarks.

\section{Literature Review}

Risk and uncertainty constantly plagued construction industry compared with other business activities due to its characteristics of complexity, dynamism and time pressure. 
Notwithstanding its positive economic and social impacts, construction industry has in fact, a major drawback in being one of the most unsafe for workers. Data from a number of industrialized countries show that construction workers are 3 to 4 times more likely than other workers to die from accidents at work. In developing countries, the risks associated with construction work may be 3 to 6 times greater (International Labour Organization, 2009).

The above mentioned challenges motivated us to start our research looking for a methodology that can provide a reliable assessment for the different types of risks associated to this industrial sector.

According to Masera and Mecca (1999), who mentioned FMEA technique as the most important tool in managing quality plans within the building construction sector, our belief is also that FMEA has a very strong potential to be a powerful risk assessment tool for the construction domain.

We therefore endeavoured to develop an improved version on FMEA that can provide promising results in particular when considering the construction domain idiosyncrasies.

For this aim, in the next section, we present an overview of traditional FMEA in the construction industry and its shortcomings.

\subsection{An Overview on FMEA methodology}

As mentioned above, Masera and Mecca (1999) pointed out how FMEA can be the most important tool in managing quality plans thus resulting in suitable, adequate and more efficient operations in the construction site. In fact the purpose of FMEA is to prioritize the failure modes of the product or system in order to focus scarce resources on the most critical risk areas (Liu et al., 2013).

FMEA is an analysis technique for defining, identifying and eliminating known and/or potential failures, problems, errors and so on from a system, product design, process and/or service before they reach the customer (Stamatis, 2003). When this technique is used for a criticality analysis, it is also referred to as Failure Mode, Effects and Criticality Analysis (FMECA) (Liu et al., 2013). Actually, the criticality analysis is intrinsic in the FMEA, as it is performed by mean of the risk priority number (RPN) calculation; for this reason, in the remainder of the paper, we will be using FMEA and FMECA as synonyms.

It is proved that FMEA is one of the most important primary prevention methods in system, product, process or service design (Damanaba et al. 2015)

The main objective of FMEA is to identify potential failure modes, evaluate the causes and effects of different component failure modes, and determine what could eliminate or reduce the chance of failure (Vosniakos and Barla, 2006). The results of the analysis can help analysts to identify and correct the failure modes that have a detrimental effect on the system and improve its performance during the stages of design and production (Liu et al., 2013). Traditionally, criticality or risk assessment in FMEA is carried out by developing an RNP, obtained multiplying 3 factors, called Severity, Occurrence and Detectability, ranging from 1 to 10 . The severity $(S)$ rating is used to represent the potential effects associated with the occurrence of a failure mode. "It is ranked according to the seriousness of the failure mode effect on the next higher level assembly, the system, or the user. The effects of a failure mode are normally described by the effects on the user of the product or as they would be seen by the user. For example, some common failure effects for automobiles are excessive noise, intermittent operation, impaired control, and rough ride." (Peldez and Bowles, 1995). The occurrence rating (O) is the frequency or the probability of the occurrence of the failure. (Ayyub, 2003) defined the detection rating (D) as "a measure of the capability of the current controls." The detection level (D) represents the probability of not detecting the failure. "It is an assessment of the ability of a proposed design verification program to identify a potential weakness before the part or assembly is released to production." (Peldez and Bowles 1995).

Despite the importance of FMEA as a risk assessment tool, studies on FMEA in construction industry are still in its infancy stage if compared to the application of FMEA in manufacturing industry (Ji-Won Song et al., 2007). In fact, although FMEA is a method developed in the 1970s in the industrial domain, only recently has it been adapted to the construction domain as a mean to identify all the possible "degradation" scenarios (Talon et al., 2008).

In addition, most of the authors approached the risk assessment in this sector by using FMEA in its traditional form, without considering any modifications, with the exception of some authors who proposed a modified version of FMEA, which has been combined with a fuzzy logic in most of the cases. It is worth 
mentioning, e.g., Fayek and Abdelgawad (2010), who proposed an extension application of FMEA to risk management in construction industry. He used a combination of Fuzzy Logic and Fuzzy Analytical Hierarchy process (AHP). In order to avoid the crisp evaluation of the conventional FMEA, they refined the severity (S) assessment defining three dimensions of impact (I): Cost Impact (CI), Time Impact (TI) and Scope Impact (SI). Another example is given by Fayek and Abdelgawad (2010). In their work, fuzzy logic and fuzzy Analytical Hierarchy Process (AHP) are used to address the limitations of traditional FMEA. This method explores the concept of expert systems to map the relationship among Severity, Occurrence, and Detection and the actual criticality level of risk events.

\subsection{Shortcomings of FMEA}

Fayek and Abdelgawad (2010), summarized the difficulties of applying FMEA in construction domain, namely:

- to implement an effective FMEA at each stage of the project life cycle, the up-front allocation of resources is required, which is not always feasible in construction industry;

- the identification of the potential risk events at each stage in the project life cycle is another challenge, since many root causes may interact to cause the risk event to occur.

On the other hand they provided some suggestions to overcome such difficulties:

- organizations need to create a risk-based culture in each functional area within the organization;

- applying FMEA by top management is crucial to the successful implementation of this technique.

Therefore, a promising research avenue could be focused on enhancing the application of FMEA in a proper way, as there still are many limitations regarding this methodology.

Recently, FMEA research has been focused on improving traditional FMEA limitations by using different measurement schemes, considering multiple failure scenarios, and incorporating sensitivity analysis (Rhee and Ishii, 2003; Lolli et al., 2013). Other authors demonstrated that the application of this method in various fields has revealed its weaknesses and limitations (Lolli et al., 2015) and, consequently, researchers have put great effort in reforming and strengthening its working functionalities (Damanab et al., 2015).

Traditional FMEA uses a risk priority number (RPN) to evaluate the risk level of a component or process. Many researchers pointed out how RPN method shows some important weaknesses when FMEA is applied in the some industrial cases (Mentes and Ozen, 2015). Therefore, many alternative approaches have been suggested in literature to resolve some of the shortcomings of the traditional RPN method and to implement FMEA into real world situations more efficiently.

To the best of our knowledge, the most complete classifications of FMEA shortcomings have been done by Liu et al. (2013) and by Driessen et al. (2015). These authors set the basis for further research on spare parts classification with FMEA approach and highlighted the following major shortcomings of the conventional FMEA:

1) The relative importance among $S, O$ and $D$ is not considered

2) Different combinations of $S, O$ and $D$ may produce exactly the same value of RPN, but their hidden risk implications may be totally different;

3) The three risk factors are difficult to be precisely evaluated;

4) The mathematical formula for calculating RPN is questionable and debatable;

5) The conversion of scores is different for the three risk factors;

6) The RPN cannot be used to measure the effectiveness of corrective actions;

7) RPN are not continuous with many gaps;

8) Interdependencies among various failure modes and effects are not taken into account;

9) The mathematical form adopted for calculating RPN is strongly sensitive to variations in risk factor evaluations;

10) The RPN elements have many duplicate numbers; 
11) RPN considers only three risk factors mainly in terms of safety.

Table 1 summarizes the above RPN weaknesses of the conventional FMEA with the corresponding authors (Liu et al., 2013). In addition to the shortcomings reported by Liu and Driessen, some more limitations have been lately addressed by other authors:

traditional FMEA solves a ranking problem, but a sorting problem arises for the resource allocation (Lolli et al., 2015).

Moreover, traditional FMECA does not include a procedure for selecting the corrective actions; even though the RPN values indicate the corrective priority from the perspective of risk, following RPN to prioritize corrective actions might fail to lead to significant risk reduction because FMECA disregards the effectiveness of said corrective actions. Furthermore, corrective actions may be not independent and may be in a relationship of hierarchy or even interdependence. (Lolli et al., 2016; Chen, 2017).

- Frequencies of failures do not provide any information on the frequency of causes; several causes can lead to the same failure and vice-versa (Lolli et al., 2016).

- Finally, evaluation of risk factors is definitely subjective, thus the involvement of multiple decisionmakers makes the procedure more robust; risk assessment of the FMEA is a group exercise that requires cross-functional specialists from various functions, yet literature lacks group decision support systems for sorting failures in the field of the FMEA (Lolli et al., 2015).

As reported by Liu et al. (2013), the importance of doing researches to enhance FMEA reliability has definitely been increasing over time (Figure 1).

Based on the above literature review we can state that there are many studies that deal with the problems and enhance the performance of the traditional FMEA.

\section{*** PLEASE PLACE TABLE 1 APPROXIMATELY HERE***}

\section{Research Motivations and Proposed Framework}

Despite the wide use of FMEA as a risk assessment tool aiming at improving safety and reliability of a systems, processes and services, the extant literature proves that conventional FMEA is unfit to address the risk complexity in construction industry. Yet, notwithstanding the many limits of this methodology, it still can provide a reliable result, if sufficient modifications and enhancements were provided.

Based on the analysed literature, it is very important to mention some suggestions for future researches from our point of view, which also fostered our research project aiming at developing and implementing a new methodology:

- The most prominent limitation of the conventional FMEA is using only three criticality factors in order to evaluate a failure mode, while it would be more reliable to use more criticality factors in the evaluation process. This would significantly increase the effectiveness of FMEA;

- Conventional FMEA does not take into consideration the interdependency effect of the failures, which is crucial in construction domain, as many injuries actually happen because two or more failure modes happened simultaneously;

- In order to reduce the occurrence of duplicate RPN numbers, using different weights for the criticality factors is very important;

- It is crucial to consider the "long-term" evolution of risks when analyzing the failure mode behaviour, in order to avoid errors due to inadequate information provided by the experts during the early evaluation and to take into account how the effects of the different failure modes would evolve over time (during the various stages of the construction project) in the system as a whole;

- In addition, using simple methodologies instead of complex ones would secure one of the main advantages of the conventional FMEA, namely the easiness of use.

Therefore, and based on the above objectives and research motivations, we are introducing a new approach named Composite FMEA (COMP-FMEA) based on the integration of FMEA with the Pairwise Comparison method and Markov Chain methodology. The proposed methodology consists of three main stages: 
1) Stage 1 is the same as any conventional FMEA application. It is very important and crucial to give a clear and complete idea about the sequence and the structure of the operations and the different parts and component of the system before using the methodology. In this stage, the hierarchical level at which the analysis takes place is also identified. Furthermore, it is important to choose at this stage the type of the FMEA (system, process, or design); this makes the decomposition process easier and more reliable.

2) Stage 2 is the calculation of a Weighted Risk Priority Number (WRPN) based on selection of the most significant parameters that may affect the system (Criticality Factors) forming severity factor. In fact, as mentioned in the introduction, it is more reliable to split the conventional FMEA's severity factor into several factors. These critical factors vary according to the process characteristics.

3) Then, Stage 3 carries out a re-assessment of failures with medium to low risk (WRPN lower than a specified threshold, e.g. WRPN $\leq 200$ ), by fine-tuning the probability of each risk (Braglia et al. 2007; Carmignani, 2009). In order to do so, two correction factors are introduced. The first one, named Reprioritization Correction Factor (RCF), has been designed based on the concept of Markov Chains to correct the possible mistakes of having inadequate information given by the experts during the first stage. RCF determines the risk level of each failure mode/risk in the steady state of the project (Equilibrium Stage). This factor should consider the bias of experts' estimations during the design phase. In this phase, experts appear to focus only on current risks, without looking forward and understanding what the real risk probabilities could be in the long period (i.e. during the several life-cycle phases that the typical project in the construction industry goes through). The second correction factor, named Interdependence Correction Factor (ICF), has been designed to identify the effect of the interdependence among different failure modes or risks in different system levels, which is neglected by the conventional FMEA. ICF also is applied only to failures with WRPN lower than a threshold (higher priority risks are not reassessed, as it is already clear that they demand further actions).

Figure 2 summarizes the three stages described above, giving the overall research framework.

The approach proposed in this study integrates three main methodologies: i) the conventional FMEA, ii) the Pairwise Comparison and iii) Markov Chain process. In the next sections an implementation of the methodology in a company producing pre-cast structural elements is developed and discussed. Thus, section 4 goes through the steps of the framework synthesised in Figure 2, providing all the necessary details to potential practitioners interested in applying the methodology.

\section{Case Study}

The effective development and testing of the methodology requires a real-life case study, as the parameterization of the methodology might be context-sensitive. For this purpose, a company was selected, which is active in the following sectors:

- Prefabrication and pre-casting of concrete;

- Civil and industrial construction;

- Production of calcareous materials, asphalt and ready-mixed concrete.

The company produces, transports and installs prefabricated structures able to fulfil specifications of companies and designers working in the field of civil, industrial and commercial prefabricated. The production site has a total area of 170,000 sq.m. The study has been conducted for 4 months jointly with the quality and safety manager.

The aim of the application was to show to company managers the potential of the proposal method compared to the traditional FMEA analysis.

\subsection{Stage 1}

This phase is crucial to understand the application domain, before starting implementing the methodology. 
The following four fundamental steps help the potential user in the breaking out of system and to understand its potential failures:

- Setting the application scope: the most important step in the methodology, as well as in the conventional FMEA, is to define the scope of the application. It is very important for the team to decide from which perspective the tool will be used (Design, Safety, Maintenance);

- Setting system's mission, operation and parts: this step aims at giving the team a clear and complete idea about the mission, the sequence and the structure of the operations and the different parts and components of the system or the project;

- Identify hierarchical levels at which analysis is carried out: it is important to choose the type of the FMEA - system, process, or design; this makes the decomposition process easier and more reliable. On the other hand, this step aims at better understanding the entire system; the decomposition of the system into its basic parts will make it easier to identify the possible parts that can cause failures for a specific part or for a whole module of the system;

- Identify each item to be analyzed: after the complete understanding of the system, the team has to decide which critical items have a potential to be a failure cause; the team has to analyze those items in order to identify the potential risks or failure modes.

The system selected for the analysis is the mixer ORU MS 3000/2000, shown in Figures 3a-3b, fed by an aerial cart shown in figure $4 a-4 b$. This system has been chosen because it represents the heart of the central mixing plant. It receives and blends aggregates, cement and other powders coming from the silos.

The main components of the system are the following

- Rotating tank

- Hydraulic central unit

- Electrical control panel

- Drive wheels

- Gearmotor

- Puffer

- $\quad$ Side wheels

- Encoder wheel

- Ending brake

- Siren and flashing light

- Inductive sensor for bucket

- Alligning cart fotocells

- Cart cam for limit action

The technical specification are reported in table 2

\section{*** PLEASE PLACE TABLE 2 APPROXIMATELY HERE***}

\subsubsection{System Analysis}

The decomposition of the system into its basic parts has been conducted working with the Quality and Safety manager. Figure 4 shows the decomposition of the mixer. The decomposition resulted in three main levels. In these levels we may see that the highest complexity is given by the mixing case group box, where the concrete is mixed to obtain the raw material for production.

\subsubsection{Failure modes identifications}

After the system has been analyzed, we may define the failure modes. These failures modes have been identified together with the safety manager and operators. Since the team has to analyze those items in 
order to identify the potential risks or failure modes, it consists of experts from several fields or departments.

In this analysis a total of 17 failure modes have been singled out. For each failure, a failure description is provided to understand the effect of each failure mode on the overall system. Table 2 shows the defined failure modes assigned to the different subsystems.

\section{*** PLEASE PLACE TABLE 3 APPROXIMATELY HERE***}

\subsection{Stage 2}

\subsubsection{Critical factors identification}

As mentioned, the parameters affecting this industrial sector may not limited to $\mathrm{S}, \mathrm{O}$ and $\mathrm{D}$. Therefore, in this study conventional FMEA's severity factor are split into sub-factors, depending on the process characteristics. In addition, these factors should have different importance weights, which will be defined later on using the method of Pairwise Comparison.

Based on that, the project team should identify a list of criticality factors and, at the same time, try and quantify their severity.

In this analysis, 9 critical factors have been identified with the aim to describe the severity of a failure:
1. Crushing
2. cutting or sectioning
3. Impact
4. Perforation or puncture
5. Friction or abrasion
6. Ejection of high pressure fluid
7. Sliding
8. Fall
9. Product Quality problems

These factors are inherent to mechanical risks, except the last one, which includes several sub-factors, such as:

- workability of the concrete or its consistency;

- compaction and maturation;

- non-compliance of the geometry of the finite element;

- resistance of the concrete (control of acceptance);

- durability of the construction;

- cracks or dents on the product;

- other defects of aesthetic nature.

When the criticality factors list is defined, each factor is divided into four main linguistic classes (table 4a-b) showing the different criticality levels (Wang and Pillary, 2003; Chin et al., 2009; Ying-Ming Wang et al., 2009) in a 1-to-100 scale. Guidance scales for critical factors evaluation have been developed with the support of the safety manager.

\section{*** PLEASE PLACE TABLE 4 APPROXIMATELY HERE***}

\subsubsection{PAIRWISE COMPARISON TO DETERMINE THE CRITICALITY FACTORS WEIGHT}

To determine the criticality factors weight $(\alpha)$, a simple Pairwise Comparison with two factors at one time has been adopted. A relative scale [1-9], called "semantic scale of Saaty" is used to define the relative attribute importance, as shown in table 5 (Saaty, 1990).

\section{*** PLEASE PLACE TABLE 5 APPROXIMATELY HERE***}


The next step is to develop a comparison matrix with all the factors in rows and in columns reporting the results of each pairwise comparison. In this matrix, the diagonal members are always equal to 1 . The lower comparison triangular matrix is filled using the reciprocal of the values in the upper triangular matrix.

After the comparison matrix has been worked out, a priority vector is calculated. then, based on the priority vector, the rank can be assigned to the criticality factors.

The last step, to evaluate the goodness of the judgment, is a consistency check. This check is needed because the evaluations given by decision makers may be not consistent due to the difficulty in keeping a consistency of opinions in all pair-wise comparisons. In addition, by their judgmental nature, opinions given by the decision makers may not be structurally consistent. Consistency ratio (CR) is defined as following (Saaty, 1990):

$$
C_{R}=\frac{C I}{R I}
$$

Where: $C I=$ Consistency Index for an $n \times n$ matrix

$$
R I=\text { The corresponding average random index }
$$

$$
\mathrm{CI}=\frac{\Lambda_{\max }-n}{n-1}
$$

where: $\Lambda_{\max }=$ the maximum eigenvalue of the matrix.

$$
n=\text { Number of comparisons }
$$

Judgments can be considered acceptable if $C_{R} \leq 0.1$. If $C_{R}>0.1$, single values leading to the inconsistent matrix are discarded and new comparison values are collected.

If the comparison matrix is acceptable, a Weighted RPN can be calculated using the results of the pair-wise comparisons, through the following relationship:

$$
W R P N=O i \times((F 1 \times \alpha 1+F 2 \times \alpha 2+F 3 \times \alpha 3+\cdots F i \times \alpha i) / 10) \times D i
$$

Where:

$O i=$ Occurrence Failure

$F=$ Criticality Factor Score

$i=$ Number of Criticality factors

$\alpha=$ Criticality Factor Weight

$D i=$ Detection Failure

Based on the above-mentioned analysis the matrix of table 6 is obtained to determine the criticality factors weight.

\section{*** PLEASE PLACE TABLE 6 APPROXIMATELY HERE***}

The results show a value of $\mathbf{C}_{R}=\mathbf{0 . 0 3}$ meaning that the judgement is acceptable. Thus we can step forward using the resulting weights. In the next step, a Weighted Risk Priority Number (WRPN) is calculated for each failure mode using (3). Table 7 shows the results.

\section{*** PLEASE PLACE TABLE 7 APPROXIMATELY HERE***}




\subsection{Stage 3}

After analysing the result obtained in Stage 2, the project team decided to apply the correction process to failures with Medium, Low and Very Low risk, i.e. setting the threshold for WRPN at 200 (Braglia et al.,2007; Carmignani, 2009). The value of the threshold has been selected also taking into account, pragmatically, how many failures would then have needed re-assessment; the aim is avoiding the re-assessment of highrisk failures, as their high criticality is already manifest.

In Table 7 we have highlighted in the shaded cells all the failures with a WRPN $\leq 200$. The RCF is used to correct the possible errors due to inadequate information given during the first phase. This correction factor considers the possible effect of these failures in the long term, to check whether the risk level will approximately stay the same or could increase over time.

RCF is determined through two steps, presented in the following sections.

\subsubsection{Identifying the initial risk vector and the transition matrixes}

In the first step, the failure modes are grouped based on the WRPN into five main risk groups, according to the scale of table 8.

\section{*** PLEASE PLACE TABLE 8 APPROXIMATELY HERE***}

Then, the evaluation process is iterated again for those failures with WRPN $\leq 200$. In this process the probability of each risk is evaluated. The results are set as in table 8 . Hence, the one-step transition probability can be defined as P Matrix (eq. 4):

$$
\begin{aligned}
& P=\left|\begin{array}{lllll}
\frac{P_{11}}{P_{1 T}} & \frac{P_{12}}{P_{1 T}} & \frac{P_{13}}{P_{1 T}} & \frac{P_{14}}{P_{1 T}} & \frac{P_{15}}{P_{1 T}} \\
\frac{P_{21}}{P_{2 T}} & \frac{P_{22}}{P_{2 T}} & \frac{P_{23}}{P_{2 T}} & \frac{P_{24}}{P_{2 T}} & \frac{P_{25}}{P_{2 T}} \\
\frac{P_{31}}{P_{3 T}} & \frac{P_{32}}{P_{3 T}} & \frac{P_{33}}{P_{3 T}} & \frac{P_{34}}{P_{3 T}} & \frac{P_{35}}{P_{3 T}} \\
\frac{P_{41}}{P_{4 T}} & \frac{P_{42}}{P_{4 T}} & \frac{P_{43}}{P_{4 T}} & \frac{P_{44}}{P_{4 T}} & \frac{P_{45}}{P_{4 T}} \\
\frac{P_{51}}{P_{5 T}} & \frac{P_{52}}{P_{5 T}} & \frac{P_{53}}{P_{5 T}} & \frac{P_{54}}{P_{5 T}} & \frac{P_{55}}{P_{5 T}}
\end{array}\right| \\
& \text { *** PLEASE PLACE TABLE } 8 \text { APPROXIMATELY HERE*** }
\end{aligned}
$$

This second phase supposes that the Markov Chain model is ergodic (it is possible to eventually get from every state to every other state with positive probability), thus meaning the risk distribution at each risk level remains constant after a long time (Sujiao, 2009).

The probabilities of the failures to be in a certain risk level (risk distribution) in the steady state are described as a steady state vector, which can be calculated with the following procedure. The risk distribution at the steady state is:

$$
V_{s S}=(\mathrm{V} 1, \mathrm{~V} 2, \mathrm{~V} 3, \mathrm{~V} 4, \mathrm{~V} 5)
$$

since the risks are modelled by an ergodic Markov Chain, we obtain:

$$
V_{s s}=V_{s s} \times \mathrm{P}
$$

Hence, by solving the previous equation, we can come up with steady state vector $v_{s s}$, which gives probabilities of a certain failure mode to be very low, low, medium, high or very high risky. Since we are looking for the failures with high or very high-risk level, the RCF will depend on the sum of the probabilities of being high and very high in the steady state: 
Based on this probability, the Reprioritization Correction Factor (RCF) can be set as in table 9. These values have been selected after a fine-tuning, consisting of different interviews, conducted with the quality managers.

As discussed above, the first step to calculate the RCF is to identify the One-Step Transition Matrix (OSTM). The input of this step is the Failure risk matrix, which shows the risk assessment for each failure mode at the first stage and the second stage (Early-construction stage) provided by the experts. The output is the OSTM. As an example, the failure 'F1-Unload Door' is reported (table 10-11). A similar analysis has been carried out for all the selected failures.

\section{*** PLEASE PLACE TABLES 9-10-11 APPROXIMATELY HERE***}

\subsubsection{Risk probability at the steady state}

At this step, we are interested in the risk distribution at the steady state, i.e. the long-term equilibrium stage in which each risk level remains constant. A model, developed with Matlab 5.0, is used to solve the steady state equation (6), for those failures, where $\mathbf{V}$ (SS) is the risk distribution vector at the steady state $=$ (V1, V2, V3, V4, V5).

The analysis has been done for all the failures having WRPN $\leq 200$. The final vector is reported in table 12 . Then, the RCF has been calculated by defining the probability of the failure mode to have a high or very high risk: $\mathrm{PH}, \mathrm{VH}$, where $\mathrm{PH}, \mathrm{VH}=V 4+V 5$. Table 13 shows the results.

\section{*** PLEASE PLACE TABLES 12-13 APPROXIMATELY HERE***}

\subsubsection{INTERDEPENDENCE CORRECTION FACTOR}

The Interdependence Correction Factor (ICF) has been conceived to consider the effects of the interdependency of different failures that may be neglected by the conventional FMEA. Like the RCF, the ICF is applied only to failures with WRPN $\leq 200$.

The first step to determine ICF is to define the Interdependencies Matrix (IM). The aim of this matrix is to define the possible impact of each failure mode on other failure modes. Therefore, experts should define the relationships between the different failure modes in different levels (subsystems, or components) by identifying the probability of a certain failure to be a cause of the other failures. Table 14 shows a sample of IM.

\section{*** PLEASE PLACE TABLE 14 APPROXIMATELY HERE***}

Hence, for each failure the Failure Impact Ratio (FIR) is defined as the ratio between the number of the probabilities higher than or equal to $40 \%$ and the total number of failures. This threshold comes from the observation - in the applications of the methodology - that expert's estimations over and above $40 \%$ are much more likely to have significant impact than those below that threshold. Nonetheless, this value could be fine-tuned in future studies.

$$
F I R=\frac{\text { No. of probabilities } \geq 40 \%}{\text { Total No. of failures }-1}
$$

This ratio gives an idea of the probability that a certain failure, on turn, would generate other failures (the network of interdependencies effect). Hence, a second correction factor can be set as in table 15 .

In order to determine the ICF for the failures with WRPN $\leq 200$, the IM has been developed with the support of process experts. The IM shows the effect of each the failures on the other failure modes. Table 16 shows the results of this analysis.

\section{*** PLEASE PLACE TABLES 15-16 APPROXIMATELY HERE***}




\section{Discussion and Conclusions}

The importance and the power of FMEA as a risk assessment tool and an early preventive action tool is manifest. Yet, it is very important to emphasize that, due to the complexity and unique nature of the construction and pre-cast sector, applying the conventional version of FMEA might fail to guarantee the desired level of risk reduction. Several improvements and modifications should take place in order to turn FMEA into an effective risk assessment tool for construction process. Therefore, a general and customizable tool that gives a unique risk assessment would assure more effective and reliable results.

In this study we addressed a method to overcome the conventional FMEA limitations by using Pairwise Comparison and Markov Chain methods for assessing all potential risks. The model has been applied to an industrial case study, which demonstrates the validity of the model.

In the deployment of the system for the case study, we defined several criticality factors that can better describe the severity of a failure mode. The Method of Pairwise Comparison was used for considering the relative importance of the input factors in RPN calculation. Through Pairwise Comparison we have been able to come up with a WRPN by assigning different weights for the criticality factors defined by the users, according to the importance and impact on the process. This novel approach addresses one of the major FMEA limitations: namely that i) the relative importance among $S, O$ and $D$ is not considered and ii) the three factors have the same weight.

In order to avoid errors due to inadequate information provided by the experts during the early evaluation and to take into account the long-term effects of the different failure modes in the system as a whole, a further evaluation has been carried out using Markov Chain for the failures having WRPN less than or equal to 200. This evaluation gives the possible risk distribution of a failure mode in the steady state or in the long term. On turn, this evaluation has been translated into a correction factor named Reprioritization Correction Factor.

Moreover, in order to address another limitation of the conventional FMEA concerning the fact that Interdependencies among various failure modes and effects are not considered, a further correction process is applied on the failure modes having WRPN less than or equal 200 by defining the probability of each failure to be a cause for the other failures.

At the end of the application of the COMP-FMEA, we discussed with the company the merits of the new approach. The management appreciated the possibility to better appraise all the contributions to the failures criticality. The team also analysed which components of the planetary mixer are involved in the highest RPN failures, and realised that the new methodology allows to re-focus the attention on apparently smaller, yet strongly interconnected components. 
The company shown a keen interest to apply the new methodology to other systems.

\subsection{Limits and suggestions for further researches}

Despite the above-mentioned improvements, the proposed methodology still showed some limitations that could be a starting point for future studies in this research area.

First of all, the methodology still depends on linguistic evaluation for the criticality parameters, which provide uncertainty and a certain degree of subjectivity of the information provided by experts. However, a correction process could be developed to reduce this effect, such as a further improvement using fuzzy sets in order to provide more precise evaluation.

The values of the proposed correction factors are not highly accurate. Instead, they depend on the user perspective, and, thus, could be more or less conservative. Therefore, a future work needs to be oriented towards identifying the most suitable correction factors values. In particular, it was clear during the application that the contribution of a cross-departmental team of specialists was needed; as a future development, a proper Group-Decision-Support-System (GDSS) could be introduced, to optimize the effort of the team, and turn a number of individual contributions (or opinions) into a real team-decision-making. The value of the WRPN threshold, set at 200, is context specific, and thus shall be considered appropriate only in the discussed Case Study (it might take different values in other contexts); at the same time one future development would be to formulate a more robust approach to set the threshold value, once again using a GDSS.

Another potential limitation is that the proposed method does not include a corrective action process. Therefore, what can be suggested is a future work that aims at developing a database of recommended corrective actions that are suitable for each specific risk in the different project stages, built (at least partially) upon historical data and lessons learned. Moreover, this database should contain the actual probability of each failure to move from a certain risk level in a certain project stage to a different risk level in a further project stage, which will allow having more reliable and accurate results from the use of Markov Chain.

Furthermore, another future research avenue could be a continuous application of FMEA at each stage of the project life cycle. This is somehow challenging in that it requires a risk-based culture within the organization and a collaborative on-going risk assessment process performed by each department within the organization.

\section{References}

Ayyub B. M. (2003). Risk analysis in engineering and economics. New Youk: Chapman \& Hall/CRC.

Braglia, M. (2000). MAFMA: Multi-attribute failure mode analysis. International Journal of Quality \& Reliability Management, 17, 1017-1033.

Braglia M., Fantoni G., Frosolini M. (2007). The house of reliability. International Journal of Quality \& Reliability Management, 24(4), 42-440.

Braglia M., Frosolini M., Montanari R. (2003). Fuzzy criticality assessment model for failure modes and effects analysis. International Journal of Quality \& Reliability Management, 20(4), 503-524.

Braglia M., Frosolini M., Montanari R. (2003). Fuzzy TOPSIS approach for failure mode, effects and criticality analysis. Quality and Reliability Engineering International, 19(5), 425-443.

Carmignani G. (2009). An integrated structural framework to cost-based FMECA: The priority-cost FMECA. Reliability Engineering and Systems Safety, 94(4), 861-871.

Chang C.L., Wei C.C., Lee Y.H. (1999). Failure mode and effects analysis using fuzzy method and grey theory. Kybernetes, 28(9), 1072-1080. 
Chang C.L., Liu P.H., Wei C.C. (2001). Failure mode and effects analysis using grey theory. Integrated Manufacturing Systems, 12(3), 211-216.

Chang K.H. (2009). Evaluate the orderings of risk for failure problems using a more general RPN methodology. Microelectronics Reliability, 49(12), 1586-1596.

Chang K.H., Cheng C.H., Chang Y.C. (2010). Reprioritization of failures in a silane supply system using an intuitionistic fuzzy set ranking technique. Soft Computing, 14(3), 285-298.

Chang K.H., Wen T.C. (2010). A novel efficient approach for DFMEA combining 2-tuple and the OWA operator. Expert Systems with Applications, 37(3), 2362-2370.

Chen L.H., Ko W.C. (2009a). Fuzzy linear programming models for new product design using QFD with FMEA. Applied Mathematical Modelling, 33(2), 633-647.

Chen L.H., Ko W.C. (2009b). Fuzzy approaches to quality function deployment for new product design. Fuzzy Sets and Systems, 160(18), 2620-2639.

Chen, J. K. (2017). Prioritization of Corrective Actions from Utility Viewpoint in FMEA Application. Quality and Reliability Engineering International, Vol. 33, Issue 4, pp 883-894

Chin K.S., Wang Y.M., Poon G.K.K., Yang J.B. (2009). Failure mode and effects analysis using a group-based evidential reasoning approach. Computers \& Operations Research, 1768-1779.

Chin K.S., Chan A., Yang J.B. (2008). Development of a fuzzy FMEA based product design system. International Journal of Advanced Manufacturing Technology, 633-649.

Claxton K., Campbell-Allen, N.M. (2017). Failure modes effects analysis (FMEA) for review of a diagnostic genetic laboratory process. International Journal of Quality and Reliability Management, Vol. 34, Issue 2, pp. 265-277

Damanab P. Sheikh, Alizadeh S.S., Rasoulzadeh Y., Moshashaie P., Varmazyar S. (2015). Failure modes and effects analysis (FMEA) technique: a literature review. Scientific Journal of Review 4(1) 1-6

Driessen, M., Arts, J., Van Houtum, G.-J., Rustenburg, J.W., Huisman, B. (2015), Maintenance spare parts planning and control: A framework for control and agenda for future research, Production Planning \& Control, 26 (5), pp. 407-426

Fayek A.R., Abdelgawad M. (2010). Risk Management in the Construction Industry Using Combined Fuzzy FMEA and Fuzzy AHP. Journal of Construction Engineering and Management, 136(9), 1028-1036.

Gabbrielli R., Zammori F. (2011). ANP/RPN: A Multi Criteria Evaluation of the Risk Priority Number. Quality and Reliability Engineering International, 28(1), 85-104.

Garcia P.A.A., Schirru R. (2005). A fuzzy data envelopment analysis approach for FMEA. Progress in Nuclear Energy, 46(3-4), 359-373.

Gargama H., Chaturverdi S.C. (2011). Criticality Assessment Models for Failure Mode Effects and Criticality Analysis Using Fuzzy Logic. IEEE Transactions on Reliability, 60(1), 102-110.

Geum Y., Cho Y., Park Y. (2011). A systematic approach for diagnosing service failure: Service-specific FMEA and grey relational analysis approach. Mathematical and Computer Modelling, 54(11-12), 3126-3142. 
Gilchrist W. (1993). Modelling Failure Modes and Effects Analysis. International Journal of Quality \& Reliability Management, 10(5), 16-23.

International Labour Organization - www.ilo.org. Retrieved on Septmber $28^{\text {th }}, 2017$

Kutlu A.C., Ekmekcioglu M. (2012). Fuzzy failure modes and effects analysis by using fuzzy TOPSIS-based fuzzy AHP. Expert Systems with Applications, 39(1), 61-67.

Liu H.C., Liu L., Liu N. (2013). Risk evaluation approaches in failure mode and effects analysis: A literature review. Expert Systems with Applications, 40(2), 828-838.

Liu H.C., Liu L., Bian Qi-Hao, Lin Qin-Lian, Na Dong, Xu P-C. (2011). Failure mode and effects analysis using fuzzy evidential reasoning approach and grey theory. Expert Systems with Applications, 38(4), 4403-4415.

Lolli, F., Gamberini, R., Rimini, B., Pulga, F. (2016). A revised FMEA with application to a blow moulding process. International Journal of Quality and Reliability Management, Vol. 33, Issue 7, pp. 900-919

Lolli, F., Ishizaka, A., Gamberini, R., Rimini, B., Messori, M. (2015). FlowSort-GDSS - A novel group multicriteria decision support system for sorting problems with application to FMEA. Expert Systems with Applications, Vol. 42, Issue 17-18, pp. 6342-6349

Lim P.C., Tay K.M. (2006). Fuzzy FMEA with a guided rules reduction system for prioritization of failures. International Journal of Quality \& Reliability Management, 23(8), 1047-1066.

Masera M, Mecca S. (1999). Technical risk analysis in construction by means of FMEA methodology. 5th Annual ARCOM Conference, 2, pp. 425-34.

Mentes A., Ozen E. (2015). A hybrid risk analysis method for a yacht fuel system safety. Safety Science 79, 94-104

Nepal B.P., Yadav O.P., Monplaisir L., Murat A. (2008). A framework for capturing and analyzing the failures due to system/component interactions. Quality and Reliability Engineering International, 24(3), 265-289.

Peldez C.E., Bowles J.B. (1995). Fuzzy logic prioritization of failures in a system failure mode, effects and criticality analysis. Reliability Engineering and System Safety, 200-213.

Prabhu B.S., Sankar N.R. (2001). Modified approach for prioritization of failures in a system failure mode and effects analysis. International Journal of Quality \& Reliability Management, 18(3), 324 - 336.

Raouf A., Ben-Daya M. (2006). A revised failure mode and effects analysis model. International Journal of Quality \& Reliability Management, 13(1), 49-47.

Rhee S.J., Ishii K. (2003). Using cost based FMEA to enhance reliability and serviceability. Advanced Engineering Informatics 17, 179-188

Saaty T.L. (1990). How to make a decision: The analytic hierarchy process. European Journal of Operational Research, 48(1), 9-26.

Seyed-Hosseini S.M., Safaei N., Asgharpour M.J. (2006). Reprioritization of failures in a system failure mode and effects analysis by decision making trial and evaluation laboratory technique. Reliability Engineering and System Safety, 91(8), 872-881. 
Sharma R.K., Kumar D., Kumar P. (2005). Systematic failure mode effect analysis (FMEA) using fuzzy linguistic modelling. International Journal of Quality \& Reliability Management, 22(9), 9866-1004

Sharma R.K., Kumar D., Kumar P. (2007). Modeling and analysing system failure behaviour using RCA, FMEA and NHPPP models. International Journal of Quality \& Reliability Management, 24(5), 525 - 546.

Sharma R.K., Kumar D., Kumar. P. (2008). Predicting uncertain behavior of industrial system using FM-A practical case. Applied Soft Computing Journal, 8(1), 96-109.

Sharma R.K., Kumar D., Kumar P. (2010). System failure behavior and maintenance decision making using, RCA, FMEA and FM. Journal of Quality in Maintenance Engineering, 16(1), 64 - 88.

Sharma R.K., Kumar D., Kumar P. (2007). Modeling system behavior for risk and reliability analysis using KBARM. Quality and Reliability Engineering International, 23(8), 973-998.

Song J.W., Yu J. H., Kim. C.D. (2007). Construction safety management using FMEA technique: focusing on the cases of steel frame work. Association of Researchers in Construction Management, 1, 55-63.

Stamatis D.H., (2003). Failure Mode and Effect Analysis: FMEA from Theory to Execution. American Society for Quality.

Sujiao Z. (2009). Risk Analysis of Construction Projects Based on Markov Chain. Information Processing, APCIP Asia-Pacific Conference. 1, pp. 514 - 517.

Talon A., Boissier D., Hans J., Lacasse M.A., Chorier J. (2008). FMECA and Management of Building Components. 11th International Conference on the Durability of Building Materials and Components, Istanbul, Turkey, pp. 1-9

Von Ahsen A. (2008). Cost-oriented failure mode and effects analysis. International Journal of Quality \& Reliability Management, 25(5), 466-476.

Vosniakos G.C., Barla E. (2006). A manufacturing system 'analysis for reengineering' framework for smalland medium-sized enterprises. Production Planning \& Control, 17:3, 311-321

Wang J., Pillary A. (2003). Modified failure mode and effects analysis using approximate reasoning. Reliability Engineering and System Safety, 69-85.

Wang Y.M , Chin K.S., Poon G.K.K., Yang JB. (2009). Risk evaluation in failure mode and effects analysis using fuzzy weighted geometric mean. Expert Systems with Applications, 36(2), 1195-1207.

Xiao N., Huang H.Z., Li Y., He L., Jin T. (2011). Multiple failure modes analysis and weighted risk priority number evaluation in FMEA. Engineering Failure Analysis, 18(4), 1162-1170.

Xu K., Tang L.C., Xie M., Ho S.L., Zhu M.L.. (2002). Fuzzy assessment of FMEA for engine systems. Reliability Engineering \& System Safety, 75(1), 17-29.

Yang J., Huang H. Z., He L.P., Zhu S. P., Wen D. (2011). Risk evaluation in failure mode and effects analysis of aircraft turbine rotor blades using Dempster-Shafer evidence theory under uncertainty. Engineering Failure Analysis, 18(8), 2084-2092.

Zaili Y., Bonsall S, Wang J. (2008). Fuzzy rule-based Bayesian reasoning approach for prioritization of failures in FMEA. IEEE Transactions on Reliability, 57(3), 517-528. 
Zhang Z., Chu X. (2011). Risk prioritization in failure mode and effects analysis under uncertainty. Expert Systems with Applications, 38(1), 206-214. 


\section{List of Figures}

Figure 1. Distribution of the reviewed articles

Figure 2: Research framework

Figure 3. Planetary mixer ORU MS 3000/2000

Figure 4. ORU MS 3000/2000 


\begin{tabular}{|c|c|c|}
\hline NO. & Shortcomings & Literature \\
\hline 1 & $\begin{array}{l}\text { The relative importance among } \mathrm{S} \text {, } \\
\mathrm{O} \text { and } \mathrm{D} \text { is not taken into } \\
\text { consideration }\end{array}$ & $\begin{array}{l}\text { (Von Ahsen, 2008), (Carmignani, 2009), (Gabbrielli and Zammori, 2011), } \\
\text { (Xiao et al., 2011), (Seyed-Hosseini et al., 2006), (Chang et al., 1999), } \\
\text { (Chang et al., 2001), (Sharma et al., 2005), (Sharma et al., 2007), (Sharma } \\
\text { et al. 2008), (Sharma et al., 2010), (Wang and Pillary, 2003), (Wang et al., } \\
\text { 2009), (Garcia, 2005), (Prabhu and Sankar, 2001), (Fayek and } \\
\text { Abdelgawad, 2010), (Zhang and Chu, 2011), (Chang and Wen, 2010), } \\
\text { (Kutlu and Ekmekcioglu, 2012), (Peldez and Bowles, 1995), (Nepal et al., } \\
\text { 2008), (Yang et al., 2008), (Lim and Tay, 2006), }\end{array}$ \\
\hline 2 & $\begin{array}{l}\text { Different combinations of } \mathrm{S}, \mathrm{O} \text { and } \\
\mathrm{D} \text { may produce exactly the same } \\
\text { value of RPN, but their hidden risk } \\
\text { implications may be totally } \\
\text { different }\end{array}$ & $\begin{array}{l}\text { (Von Ahsen, 2008), (Carmignani, 2009), (Braglia et al., 2003), (Chang et } \\
\text { al., 1999), (Chang et al., 2001), (Lolli et al., 2015), (Sharma et al., 2005), } \\
\text { (Sharma et al., 2007a), (Sharma et al., 2008), (Sharma et al., 2010), } \\
\text { (Wang and Pillary, 2003), (Wang et al., 2009), (Zhang and Chu, 2011), } \\
\text { (Kutlu and Ekmekcioglu, 2012), (Zaili et al., 2008), (Lim and Tay, 2006) }\end{array}$ \\
\hline 3 & $\begin{array}{l}\text { The three risk factors are difficult } \\
\text { to be precisely evaluated }\end{array}$ & $\begin{array}{l}\text { (Xu et al., 2002), (Gabbrielli and Zammori, 2011), (Yang et al., 2011), } \\
\text { (Chang and Wen, 2010), (Chang et al. ,2010), (Braglia, 2000), (Claxton } \\
\text { and Campbell-Allen, 2017), (Wang et al., 2009), (Gargama and } \\
\text { Chaturverdi, 2011), (Chen and Ko, 2009a), (Chen and Ko, 2009b), (Lolli et } \\
\text { al., 2016), (Garcia and Schirru , 2005), (Fayek and Abdelgawad, 2010), } \\
\text { (Kutlu and Ekmekcioglu, 2012), (Zaili et al., 2008), }\end{array}$ \\
\hline 4 & $\begin{array}{l}\text { The mathematical formula for } \\
\text { calculating RPN is questionable } \\
\text { and debatable }\end{array}$ & $\begin{array}{l}\text { (Gilchrist, 1993), (Raouf and Ben-Daya, 2006), (Chang et al., 1999), } \\
\text { (Chang et al., 2001), (Geum et al., 2011), (Gargama and Chaturverdi, } \\
\text { 2011), (Kutlu and Ekmekcioglu , 2012), (Sharma et al., 2005) }\end{array}$ \\
\hline 5 & $\begin{array}{l}\text { The conversion of scores is } \\
\text { different for the three risk factors }\end{array}$ & $\begin{array}{l}\text { (Gilchrist, 1993), (Raouf and Ben-Daya, 2006), (Ahsen, 2008), } \\
\text { (Carmignani, 2009), (Chin et al., 2009), (Chang et al., 1999), (Chang et } \\
\text { al., 2001), (Sharma et al., 2007b), (Gargama and Chaturverdi, 2011), } \\
\text { (Prabhu and Sankar, 2001), (Liu et al., 2011) }\end{array}$ \\
\hline 6 & \begin{tabular}{|l} 
The RPN cannot be used to \\
measure the effectiveness of \\
corrective actions
\end{tabular} & $\begin{array}{l}\text { (Gilchrist, 1993), (Raouf and Ben-Daya, 2006), (Carmignani, 2009), (Chang } \\
\text { et al., 1999), (Chang et al., 2001), (Wang and Pillary, 2003), (Gargama and } \\
\text { Chaturverdi, 2011), (Zaili et al., 2008), (Chen, 2017) }\end{array}$ \\
\hline 7 & $\begin{array}{l}\text { RPNs are not continuous with } \\
\text { many holes }\end{array}$ & $\begin{array}{l}\text { (Carmignani, 2009), (Chang and Wen, 2010), (Chang et al., 2010), (H.C. } \\
\text { Liu, 2012), (Garcia, 2005), (Chang, 2009) }\end{array}$ \\
\hline 8 & $\begin{array}{l}\text { Interdependencies among various } \\
\text { failure modes and effects are not } \\
\text { taken into account }\end{array}$ & $\begin{array}{l}\text { (Xu et al., 2002), (Chin et al., 2008), (M. Braglia, 2007), (Ahsen, 2008), } \\
\text { (Carmignani, 2009), (Gabbrielli and Zammori, 2011) }\end{array}$ \\
\hline 9 & $\begin{array}{l}\text { The mathematical form adopted } \\
\text { for calculating the RPN is strongly } \\
\text { sensitive to variations in risk } \\
\text { factor evaluations }\end{array}$ & $\begin{array}{l}\text { (Chin et al., 2009), (Gargama and Chaturverdi, 2011), (Chang, 2009), } \\
\text { (Kutlu and Ekmekcioglu ,2012), (Lolli et al., 2015), (Zaili et al., 2008) }\end{array}$ \\
\hline 10 & $\begin{array}{l}\text { The RPN elements have many } \\
\text { duplicate numbers }\end{array}$ & $\begin{array}{l}\text { (Seyed-Hosseini et al., 2006), (Chang and Wen, 2010), (Gargama and } \\
\text { Chaturverdi, 2011), (Garcia and Schirru, 2005), (Prabhu and Sankar, } \\
\text { 2001), (Chang, 2009) }\end{array}$ \\
\hline 11 & $\begin{array}{l}\text { The RPN considers only three risk } \\
\text { factors mainly in terms of safety }\end{array}$ & $\begin{array}{l}\text { (Carmignani, 2009), (Gabbrielli and Zammori, 2011), (Chin et al., 2009), } \\
\text { (Braglia, 2000), (Liu et al., 2011), (Yang et al., 2011) }\end{array}$ \\
\hline
\end{tabular}

Table. 1: FMEA shortcomings 


\begin{tabular}{|l|l|}
\hline Technical specifications ORU Mixer EDC 3000/2000 & Value \\
\hline Hopper Capacity [litres] & 4000 \\
\hline Vibrated concrete capacity [litres] & 2000 \\
\hline Max cart speed [m/sec] & 4 \\
\hline $360^{\circ}$ Rotation time [sec] & 40 \\
\hline Empty Weight [Kg] & 2450 \\
\hline Idle weight [Kg] & 7450 \\
\hline Gearmotor power [kW] & 16 \\
\hline Control unit power [kW] & 4 \\
\hline Noise [dB/A] & -80 \\
\hline
\end{tabular}

Table 2-Mixer technical specifications 


\begin{tabular}{|c|c|c|c|c|}
\hline \multirow{6}{*}{ 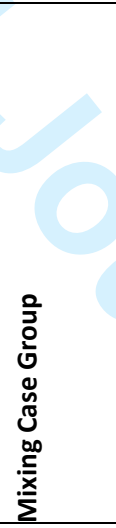 } & $\begin{array}{l}\text { Failure } \\
\text { No. }\end{array}$ & $\begin{array}{l}\text { Failure } \\
\text { Ref. }\end{array}$ & Description & Failure \\
\hline & F1 & F1.1 & $\begin{array}{l}\text { - Poor cleaning } \\
\text { - Poor maintenance } \\
\text { - Failures of the hydraulic components }\end{array}$ & Mixer unload doors are blocked \\
\hline & F2 & F1.2 & $\begin{array}{l}\text { - Lack of lubrication } \\
\text { - Poor maintenance /cleaning }\end{array}$ & $\begin{array}{l}\text { Upper reduction unit is damaged } \\
\text { or locked }\end{array}$ \\
\hline & F3 & F1.3 & $\begin{array}{l}\text { - Lack of lubrication } \\
\text { - Poor maintenance /cleaning }\end{array}$ & $\begin{array}{l}\text { Lower reduction unit is damaged } \\
\text { or locked }\end{array}$ \\
\hline & F4 & F1.4 & $\begin{array}{l}\text { - Lack of oil in the hydraulic system } \\
\text { - Poor maintenance /cleaning } \\
\text { - Problems/faults within the hydraulic system }\end{array}$ & $\begin{array}{l}\text { The cover of the mixing case } \\
\text { group does not close }\end{array}$ \\
\hline & F5 & F1.5 & $\begin{array}{l}\text { - Lack of oil in the planetary gear } \\
\text { - Poor maintenance }\end{array}$ & Planetary gear breaks \\
\hline 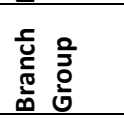 & F6 & F2.1 & $\begin{array}{l}\text { - Lack of lubricant for rotating arms } \\
\text { - Poor maintenance /cleaning } \\
\text { - Faults to the electrical motor }\end{array}$ & $\begin{array}{l}\text { The mixer rotating arms are } \\
\text { locked }\end{array}$ \\
\hline $\begin{array}{l}\frac{0}{0} \\
\frac{\pi}{0} \\
\frac{\pi}{0}\end{array}$ & F7 & F3.1 & $\begin{array}{l}\text { Poor cleaning/maintenance of the blade (to do } \\
\text { everyday) }\end{array}$ & The blade are damaged or dirty \\
\hline \multirow{3}{*}{ 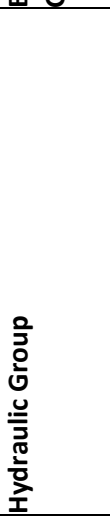 } & F8 & F4.1 & $\begin{array}{l}\text { - Poor maintenance /cleaning } \\
\text { - Using oil having inadequate characteristics (ex. too } \\
\text { high viscosity) } \\
\text { - Corrosion }\end{array}$ & $3 \mathrm{KW}$ engine is damaged \\
\hline & F9 & F4.2 & $\begin{array}{l}\text { - Clogged filter } \\
\text { - pressure valve breakdown } \\
\text { - Pump breakdown } \\
\text { - Poor maintenance /cleaning } \\
\text { - Corrosion } \\
\text { - Using oil having inadequate characteristics (e.g. } \\
\text { viscosity too high) }\end{array}$ & $\begin{array}{l}\text { Hydraulic control unit is } \\
\text { damaged }\end{array}$ \\
\hline & F10 & F4.3 & $\begin{array}{l}\text { - Poor maintenance } \\
\text { - Pressure level of oil too high } \\
\text { - Temperature level of oil too high } \\
\end{array}$ & $\begin{array}{l}7 \text { liters tank is damaged or } \\
\text { pierced }\end{array}$ \\
\hline \multirow{5}{*}{$\begin{array}{l}\sum_{2}^{n} \\
+\frac{1}{10} \\
\frac{\pi}{2} \\
\frac{0}{20} \\
\frac{0}{2} \\
\frac{10}{10} \\
3\end{array}$} & F11 & F5.1 & $\begin{array}{l}\text { - Poor cleaning } \\
\text { - Poor maintenance } \\
\text { - Wear }\end{array}$ & $\begin{array}{l}\text { 80W Multi-rotating heads are } \\
\text { damaged or are not able to clean } \\
\text { the machine }\end{array}$ \\
\hline & F12 & F5.2 & $\begin{array}{l}\text { - Poor cleaning of the gun nozzle } \\
\text { - Leaks } \\
\text { - clogged filter } \\
\text { - Too high pressure }\end{array}$ & Washing gun pipe is damaged \\
\hline & F13 & F5.3 & $\begin{array}{l}\text { - Poor cleaning } \\
\text { - Poor maintenance } \\
\text { - Wear }\end{array}$ & $\begin{array}{l}\text { LC200 Multi-rotating heads are } \\
\text { damaged or not able to clean the } \\
\text { machine }\end{array}$ \\
\hline & F14 & F5.4 & $\begin{array}{l}\text { - Excessive supply flow } \\
\text { - Excessive pressure calibration } \\
\text { - Shaft and pump components damaged } \\
\text { - Leaks }\end{array}$ & Piston pump Group is damaged \\
\hline & F15 & F5.5 & $\begin{array}{l}\text { - Wear } \\
\text { - Electrical control unit faults }\end{array}$ & Warning lights are not working \\
\hline 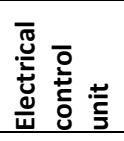 & F16 & F6.1 & $\begin{array}{l}\text { - Wear } \\
\text { - Electrical control unit faults }\end{array}$ & Siren/Alarm are not working \\
\hline 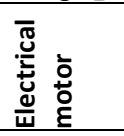 & F17 & F7.1 & $\begin{array}{l}\text { - Missed maintenance } \\
\text { - Overloaded } \\
\text { - Poor cleaning }\end{array}$ & $\begin{array}{l}110 \mathrm{KW} \text { Electrical motor is } \\
\text { damaged }\end{array}$ \\
\hline
\end{tabular}

Table 3: The defined failure modes- ORU MS 3000/2000 


\begin{tabular}{|c|l|c|}
\hline \multicolumn{3}{|c|}{ Product quality Criticality (final product) } \\
$\begin{array}{c}\text { Highly } \\
\text { Probable }\end{array}$ & $\begin{array}{l}\text { There is a direct correlation between the failure mode taken into consideration and the } \\
\text { final quality of the product. }\end{array}$ & $76-100$ \\
\hline Probable & $\begin{array}{l}\text { The lack of processability of the detected failure mode might have consequences on the } \\
\text { final quality of the product, even if not in an automatic or direct way. Few episodes are } \\
\text { known where this lack was actually followed by a damage. }\end{array}$ & $51-75$ \\
\hline $\begin{array}{c}\text { Mildly } \\
\text { Probable }\end{array}$ & $\begin{array}{l}\text { The lack of processability of the detected failure mode can cause a damage on the final } \\
\text { quality of the product under certain circumstances. Only rare episodes are known. The } \\
\text { occurrence of the damage would raise a certain surprise. }\end{array}$ & $26-50$ \\
\hline Unlikely & $\begin{array}{l}\text { The lack of processability of the detected failure mode can cause a damage on the final } \\
\text { quality of the product for a combination of several improbable independent events. No } \\
\text { episodes have already occurred. The occurrence of damage would create disbelief. }\end{array}$ & $1-25$ \\
\hline
\end{tabular}

Table 4b. Product quality Criticality 


\begin{tabular}{|c|c|}
\hline$a_{i j}$ & Interpretation \\
\hline 1 & $\mathrm{i}$ and $\mathrm{j}$ have the same importance \\
\hline 3 & $\mathrm{i}$ is little more important than $\mathrm{j}$ \\
\hline 5 & i is considerably important than $\mathrm{j}$ \\
\hline 7 & $\mathrm{i}$ is far more important than $\mathrm{j}$ \\
\hline 9 & $\mathrm{i}$ is absolutely more important than $\mathrm{j}$ \\
\hline $1 / 3$ & $\mathrm{i}$ is little less important than $\mathrm{j}$ \\
\hline $1 / 5$ & $\mathrm{i}$ is considerably less important than $\mathrm{j}$ \\
\hline $1 / 7$ & i is far less important than $\mathrm{j}$ \\
\hline $1 / 9$ & $\mathrm{i}$ is absolutely less important than $\mathrm{j}$ \\
\hline $2 ; 4 ; 6 ; 8$ & intermediate values, when a compromise is necessary. \\
\hline
\end{tabular}

Table 5. Scale for the criticality factors weight $(\alpha)$ 


\begin{tabular}{|l||l||l||l||l|l||l||l||l||l||l|}
\hline \hline & Crushing & $\begin{array}{l}\text { Cutting or } \\
\text { sectioning }\end{array}$ & Impact & $\begin{array}{l}\text { Perforation } \\
\text { or } \\
\text { puncture }\end{array}$ & $\begin{array}{l}\text { Friction or } \\
\text { abrasion }\end{array}$ & $\begin{array}{l}\text { Ejection of high } \\
\text { pressure fluid }\end{array}$ & Sliding & Fall & Quality & Weight \\
\hline Crushing & $\mathbf{1}$ & 5 & 5 & $1 / 3$ & 5 & 5 & 5 & 5 & 7 & 0.236 \\
\hline \hline $\begin{array}{l}\text { Cutting or } \\
\text { sectioning }\end{array}$ & $1 / 5$ & 1 & 3 & 3 & 3 & 5 & 3 & 3 & 5 & 0.177 \\
\hline \hline Impact & $1 / 5$ & $1 / 3$ & 1 & $1 / 3$ & $1 / 5$ & $1 / 5$ & 3 & 3 & 7 & 0.061 \\
\hline \hline $\begin{array}{l}\text { Perforation } \\
\text { or puncture }\end{array}$ & 3 & $1 / 3$ & 3 & 1 & 5 & 5 & 5 & 7 & 9 & 0.229 \\
\hline \hline $\begin{array}{l}\text { Friction or } \\
\text { abrasion }\end{array}$ & $1 / 5$ & $1 / 3$ & 5 & $1 / 5$ & 1 & $1 / 5$ & 3 & 3 & 5 & 0.079 \\
\hline \hline $\begin{array}{l}\text { Ejection of } \\
\text { high } \\
\text { pressure } \\
\text { fluid }\end{array}$ & $1 / 5$ & $1 / 5$ & 5 & $1 / 5$ & 5 & 1 & & 3 & 7 & 0.117 \\
\hline \hline Sliding & $1 / 5$ & $1 / 3$ & $1 / 3$ & $1 / 5$ & $1 / 3$ & $1 / 5$ & 1 & 3 & 7 & 0.047 \\
\hline \hline Fall & $1 / 5$ & $1 / 3$ & $1 / 3$ & $1 / 7$ & $1 / 3$ & $1 / 3$ & $1 / 3$ & 1 & 7 & 0.036 \\
\hline \hline Quality & $1 / 7$ & $1 / 5$ & $1 / 7$ & $1 / 9$ & $1 / 5$ & $1 / 7$ & $1 / 7$ & $1 / 7$ & $\mathbf{1}$ & 0.013 \\
\hline
\end{tabular}

Table 6. Pairwise Comparison 


\begin{tabular}{|c|c|c|c|c|c|c|c|c|c|c|c|c|}
\hline $\begin{array}{l}\text { Failure } \\
\text { N. } \\
\end{array}$ & O & Crushing & $\begin{array}{l}\text { Cutting } \\
\text { or } \\
\text { sectioning }\end{array}$ & Impact & $\begin{array}{l}\text { Perforat } \\
\text { ion or } \\
\text { punctur } \\
\text { e } \\
\end{array}$ & $\begin{array}{l}\text { Friction or } \\
\text { abrasion }\end{array}$ & $\begin{array}{l}\text { Ejection } \\
\text { of high } \\
\text { pressure } \\
\text { fluid } \\
\end{array}$ & Sliding & Fall & Quality & D & WRPN \\
\hline F1 & 8 & 10 & 10 & 10 & 10 & 10 & 10 & 10 & 10 & 70 & 4 & 35 \\
\hline $\mathrm{F} 2$ & 8 & 30 & 10 & 50 & 10 & 50 & 10 & 10 & 10 & 70 & 5 & 100 \\
\hline F3 & 8 & 30 & 10 & 50 & 10 & 50 & 10 & 10 & 10 & 70 & 5 & 49 \\
\hline $\mathrm{F} 4$ & 7 & 10 & 10 & 40 & 10 & 10 & 10 & 10 & 10 & 10 & 6 & 37 \\
\hline F5 & 7 & 30 & 10 & 50 & 10 & 10 & 10 & 10 & 10 & 70 & 2 & 9 \\
\hline F6 & 8 & 20 & 20 & 50 & 10 & 50 & 10 & 10 & 10 & 80 & 4 & 17 \\
\hline F7 & 8 & 20 & 20 & 50 & 10 & 50 & 10 & 10 & 10 & 80 & 4 & 282 \\
\hline F8 & 8 & 10 & 10 & 50 & 10 & 10 & 10 & 50 & 10 & 80 & 5 & 444 \\
\hline F9 & 8 & 10 & 10 & 50 & 10 & 10 & 50 & 50 & 10 & 80 & 5 & 504 \\
\hline F10 & 8 & 10 & 10 & 50 & 10 & 10 & 10 & 50 & 10 & 30 & 5 & 460 \\
\hline F11 & 7 & 10 & 10 & 10 & 10 & 10 & 50 & 10 & 10 & 70 & 4 & 392 \\
\hline F12 & 7 & 10 & 10 & 10 & 10 & 10 & 50 & 10 & 10 & 70 & 4 & 349 \\
\hline F13 & 7 & 10 & 10 & 10 & 10 & 10 & 50 & 10 & 10 & 70 & 4 & 431 \\
\hline F14 & 7 & 10 & 10 & 10 & 10 & 10 & 50 & 10 & 10 & 70 & 5 & 518 \\
\hline F15 & 5 & 10 & 10 & 10 & 10 & 10 & 10 & 10 & 10 & 10 & 2 & 84 \\
\hline F16 & 5 & 10 & 10 & 10 & 10 & 10 & 10 & 10 & 10 & 10 & 2 & 74 \\
\hline F17 & 7 & 10 & 10 & 60 & 10 & 50 & 10 & 10 & 10 & 90 & 2 & 175 \\
\hline
\end{tabular}

\section{Table 7. WRPN for ORU Mixer}




\begin{tabular}{|c|c|c|c|c|c|c|c|}
\hline & \multirow{2}{*}{ Risk level } & \multicolumn{6}{|c|}{ Second Stage (Early stage) } \\
\hline & & Very low & Low & Medium & High & Very high & TOTAL \\
\hline \multirow{5}{*}{ 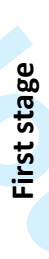 } & Very low & $\mathrm{P}_{\mathrm{q} 1}$ & $\mathrm{P}_{12}$ & $\mathrm{P}_{13}$ & $\mathrm{P}_{14}$ & $P_{15}$ & $P_{1 T}$ \\
\hline & Low & $P_{21}$ & $\mathrm{P}_{22}$ & $P_{23}$ & $P_{24}$ & $P_{25}$ & $\mathrm{P}_{2 \mathrm{~T}}$ \\
\hline & Medium & $P_{31}$ & $P_{32}$ & $P_{33}$ & $P_{34}$ & $P_{35}$ & $P_{3 T}$ \\
\hline & High & $\mathrm{P}_{41}$ & $\mathrm{P}_{42}$ & $P_{43}$ & $\mathrm{P}_{44}$ & $\mathrm{P}_{45}$ & $\mathrm{P}_{4 \mathrm{~T}}$ \\
\hline & $\begin{array}{l}\text { Very } \\
\text { High }\end{array}$ & $\mathrm{P} 5_{1}$ & $P_{52}$ & $P_{53}$ & $P_{54}$ & $P_{55}$ & $P_{5 T}$ \\
\hline
\end{tabular}

Table 8. Failure risk matrix 


\begin{tabular}{|c|c|c|c|c|c|c|c|}
\hline \multirow{8}{*}{ 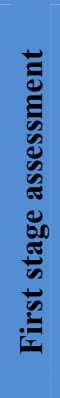 } & \multicolumn{7}{|c|}{ Second stage assessment } \\
\hline & Risk level & Very low & Low & Medium & High & Very high & Total \\
\hline & Very low & 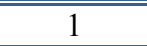 & 2 & 3 & 4 & 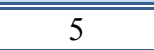 & 15 \\
\hline & Low & 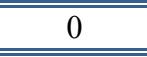 & 1 & 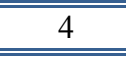 & 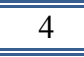 & 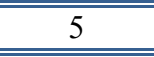 & 14 \\
\hline & Medium & 0 & 0 & 1 & 4 & 25 & 10 \\
\hline & High & 0 & 0 & 0 & 4 & $\overline{5}$ & 9 \\
\hline & Very high & 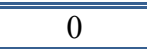 & 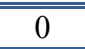 & 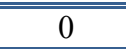 & 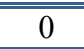 & 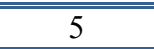 & 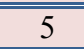 \\
\hline & Total & 1 & 3 & 8 & 16 & 25 & 53 \\
\hline
\end{tabular}

Table 10 - Failure Risk Matrix (F1 - Unload Door) 


\begin{tabular}{|c|c|c|c|c|c|c|c|}
\hline \multirow{7}{*}{ 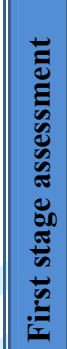 } & \multicolumn{7}{|c|}{ Second stage assessment } \\
\hline & Risk level & Very low & Low & Medium & High & Very high & Total \\
\hline & Very low & 0.067 & 0.133 & 0.200 & 0.267 & 0.333 & 1 \\
\hline & Low & 0.000 & 0.071 & 0.286 & 0.286 & 0.357 & 1 \\
\hline & Medium & 0.000 & 0.000 & 0.100 & 0.400 & 0.500 & 1 \\
\hline & High & 0.000 & 0.000 & 0.000 & 0.444 & 0.556 & 1 \\
\hline & Very high & 0.000 & 0.000 & 0.000 & 0.000 & 1.000 & 1 \\
\hline & Total & 0.067 & 0.205 & 0.586 & 1.397 & 2.746 & \\
\hline
\end{tabular}

Table 11 - The One-Step Transition Matrix (F1 - Unload Door) 


\begin{tabular}{|c|c|c|c|c|c|c|}
\hline & \multicolumn{5}{|c|}{ The Probability at steady state } & \\
\hline & V1 & V2 & V3 & V4 & V5 & \\
\hline Failure & Very low & Low & Medium & High & Very high & Total \\
\hline F1 & 0.00126 & 0.00656 & 0.03504 & 0.21575 & 0.74139 & 1 \\
\hline F2 & 0.42677 & 0.42677 & 0.12563 & 0.01157 & 0.00926 & 1 \\
\hline $\mathrm{F3}$ & 0.00244 & 0.00244 & 0.05735 & 0.33596 & 0.60181 & 1 \\
\hline F4 & 0.00111 & 0.00778 & 0.10556 & 0.25111 & 0.63444 & 1 \\
\hline F5 & 0.00111 & 0.00778 & 0.10556 & 0.25111 & 0.63444 & 1 \\
\hline F6 & 0 & 0 & 0.02826 & 0.23077 & 0.74097 & 1 \\
\hline F15 & 0.05861 & 0.20897 & 0.4011 & 0.18132 & 0.15 & 1 \\
\hline F16 & 0.05861 & 0.20897 & 0.4011 & 0.18132 & 0.15 & 1 \\
\hline F17 & 0.50969 & 0.31069 & 0.15062 & 0.02175 & 0.00725 & 1 \\
\hline
\end{tabular}

Table 12: Risk distribution at Steady State 


\begin{tabular}{c|c|c}
\hline Failure & $\mathbf{P}_{\mathbf{H}, \mathbf{V H}}$ & $\mathbf{R C F}$ \\
\hline F1 & $95,71 \%$ & $\mathbf{5}$ \\
\hline F2 & $2,08 \%$ & $\mathbf{1}$ \\
\hline F3 & $93,78 \%$ & $\mathbf{5}$ \\
\hline F4 & $88,56 \%$ & $\mathbf{4}$ \\
\hline F5 & $88,56 \%$ & $\mathbf{4}$ \\
\hline F6 & $97,17 \%$ & $\mathbf{5}$ \\
\hline F15 & $33,13 \%$ & $\mathbf{2}$ \\
\hline F16 & $33,13 \%$ & $\mathbf{2}$ \\
\hline F17 & $2,90 \%$ & $\mathbf{1}$ \\
\hline
\end{tabular}

Table 13. RCF for failures with WRPN $\leq 200$ 
The probability of a certain failure to be a cause of the other failures

\begin{tabular}{|c|c|c|c|c|c|c|}
\hline Failure & $\mathbf{F}_{\mathbf{1}}$ & $\mathbf{F}_{\mathbf{2}}$ & $\mathbf{F}_{\mathbf{3}}$ & $\mathbf{F}_{\mathbf{4}}$ & $\ldots$ & $\mathbf{F}_{\mathbf{i}}$ \\
\hline $\mathbf{F}_{\mathbf{1}}$ & 0 & $\mathrm{P}_{12}$ & $\mathrm{P}_{13}$ & $\mathrm{P}_{14}$ & $\ldots$ & $\mathrm{P}_{1 \mathrm{i}}$ \\
\hline $\mathbf{F}_{\mathbf{2}}$ & $\mathrm{P}_{21}$ & 0 & $\mathrm{P}_{23}$ & $\mathrm{P}_{24}$ & $\ldots$ & $\mathrm{P}_{2 \mathrm{i}}$ \\
\hline $\mathbf{F}_{\mathbf{3}}$ & $\mathrm{P}_{31}$ & $\mathrm{P}_{32}$ & 0 & $\mathrm{P}_{34}$ & $\ldots$ & $\mathrm{P}_{3 \mathrm{i}}$ \\
\hline $\mathbf{F}_{\mathbf{4}}$ & $\mathrm{P}_{41}$ & $\mathrm{P}_{42}$ & $\mathrm{P}_{43}$ & 0 & $\ldots$ & $\mathrm{P}_{4 \mathrm{i}}$ \\
\hline$\ldots$ & $\ldots$ & $\ldots$ & $\ldots$ & $\ldots$ & $\ldots$ & $\ldots$ \\
\hline $\mathbf{F}_{\mathrm{i}}$ & $\mathrm{P}_{\mathrm{i} 1}$ & $\mathrm{P}_{\mathrm{i} 2}$ & $\mathrm{P}_{\mathrm{i} 3}$ & $\mathrm{P}_{\mathrm{i} 4}$ & $\ldots$ & 0 \\
\hline
\end{tabular}

Table 14. The Interdependencies Matrix 


1
2
3
4
5
6
7
8
9
10
11
12
13
14
15
16
17
18
19
20
21
22
23
24
25
26
27
28
29
30
31
32
33
34
35
36
37
38
39
40
41
42
43
44
45
58
49
50
51
52
54
55
50

\begin{tabular}{|c|c|}
\hline FIR & ICF \\
\hline $0-10 \%$ & 1 \\
\hline $10-20 \%$ & 2 \\
\hline $20-30 \%$ & 3 \\
\hline $30-40 \%$ & 4 \\
\hline $40-50 \%$ & 5 \\
\hline $50-60 \%$ & 6 \\
\hline $60-70 \%$ & 7 \\
\hline $80-90 \%$ & 8 \\
\hline $90-100 \%$ & 9 \\
\hline
\end{tabular}

Table 15. Interdependence Correction Factor (ICF)

16

17

18

19

20

21

22

23

24

26

27

28

29

30

31

33

34

35

36

37

38

39

40

41

42

44

45

46

47

48

49

50

51

52

55

56

57

58

59

60

http://mc.manuscriptcentral.com/ijqrm 


\begin{tabular}{|c|c|c|c|c|c|c|c|c|c|c|}
\hline \multicolumn{10}{|c|}{ Probability of a certain failure to be a cause of the other failures } & \multirow[b]{2}{*}{ N.ro of probabilities $\geq 40$} \\
\hline Failure & F1 & F2 & F3 & F4 & F5 & F6 & F15 & F16 & F17 & \\
\hline F1 & 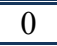 & 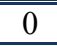 & 0 & 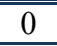 & 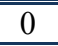 & 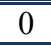 & 0 & 0 & 0 & $\overline{\mathbf{0}}$ \\
\hline $\mathbf{F 2}$ & 0 & 0 & 80 & 10 & 80 & 90 & 0 & 0 & 40 & 4 \\
\hline F3 & 70 & 80 & 0 & 0 & 80 & 90 & 0 & 0 & 40 & 5 \\
\hline F4 & 0 & 0 & 0 & 0 & 0 & 50 & 0 & 0 & 0 & 1 \\
\hline F5 & 40 & 80 & 80 & 0 & 0 & 90 & 0 & 0 & 40 & 5 \\
\hline F6 & 0 & 70 & 70 & 0 & 70 & 0 & 0 & 0 & 60 & 4 \\
\hline F7 & 0 & 20 & 20 & 0 & 20 & 30 & 0 & 0 & 30 & $\mathbf{0}$ \\
\hline F8 & 80 & 60 & 60 & 70 & 60 & 40 & 0 & 0 & 20 & 6 \\
\hline F9 & 80 & 70 & 70 & 70 & 70 & 40 & 0 & 0 & 20 & 6 \\
\hline F10 & 80 & 60 & 60 & 70 & 60 & 40 & 0 & 0 & 20 & 6 \\
\hline F11 & 10 & 20 & 20 & 10 & 20 & 40 & 0 & 0 & 10 & 1 \\
\hline F12 & 10 & 20 & 20 & 10 & 20 & 40 & 0 & 0 & 10 & 1 \\
\hline F13 & 10 & 20 & 20 & 10 & 20 & 40 & 0 & 0 & 10 & 1 \\
\hline F14 & 10 & 20 & 20 & 10 & 20 & 40 & 0 & 0 & 10 & 1 \\
\hline F15 & 0 & 0 & 0 & 0 & 0 & 0 & 0 & 0 & 0 & $\mathbf{0}$ \\
\hline F16 & 0 & 0 & 0 & 0 & 0 & 0 & 0 & 0 & 0 & $\mathbf{0}$ \\
\hline F17 & 0 & 60 & 60 & 0 & 60 & 80 & 0 & 0 & 0 & 3 \\
\hline
\end{tabular}

Table 16. Probability of a certain failure to be a cause of the other failures. 


\begin{tabular}{|c|c|c|}
\hline Failure & FIR & ICF \\
\hline F1 & $0,00 \%$ & $\mathbf{1}$ \\
\hline F2 & $25,00 \%$ & $\mathbf{3}$ \\
\hline F3 & $31,25 \%$ & $\mathbf{4}$ \\
\hline F4 & $6,25 \%$ & $\mathbf{1}$ \\
\hline F5 & $31,25 \%$ & $\mathbf{4}$ \\
\hline F6 & $25,00 \%$ & $\mathbf{3}$ \\
\hline F7 & $0,00 \%$ & $\mathbf{1}$ \\
\hline F8 & $37,50 \%$ & $\mathbf{4}$ \\
\hline F9 & $37,50 \%$ & $\mathbf{4}$ \\
\hline F10 & $37,50 \%$ & $\mathbf{4}$ \\
\hline F11 & $6,25 \%$ & $\mathbf{1}$ \\
\hline F12 & $6,25 \%$ & $\mathbf{1}$ \\
\hline F13 & $6,25 \%$ & $\mathbf{1}$ \\
\hline F14 & $6,25 \%$ & $\mathbf{1}$ \\
\hline F15 & $0,00 \%$ & $\mathbf{1}$ \\
\hline F16 & $0,00 \%$ & $\mathbf{1}$ \\
\hline F17 & $18,75 \%$ & $\mathbf{2}$ \\
\hline
\end{tabular}

Table 17. FIR and ICF 


\begin{tabular}{|c|c|c|}
\hline Failure & FIR & ICF \\
\hline F1 & $0,00 \%$ & $\mathbf{1}$ \\
\hline F2 & $25,00 \%$ & $\mathbf{3}$ \\
\hline F3 & $31,25 \%$ & $\mathbf{4}$ \\
\hline F4 & $6,25 \%$ & $\mathbf{1}$ \\
\hline F5 & $31,25 \%$ & $\mathbf{4}$ \\
\hline F6 & $25,00 \%$ & $\mathbf{3}$ \\
\hline F15 & $0,00 \%$ & $\mathbf{1}$ \\
\hline F16 & $0,00 \%$ & $\mathbf{1}$ \\
\hline F17 & $18,75 \%$ & $\mathbf{2}$ \\
\hline
\end{tabular}

Table 18. FIR and ICF for failures with RPN $<=\mathbf{2 0 0}$ 
1

2

3

4

5

6

7

8

9

10

11

12

13

14

15

16

17

18

19

20

21

22

23

24

25

26

27

28

29

30

31

32

33

34

35

36

37

38

39

40

41

42

43

44

45

46

47

48

49

50

51

52

53

54

55

56

57

58

59

60

\begin{tabular}{|c|c|c|}
\hline MRPN & Group & Legend \\
\hline $0<$ RPN $<=50$ & Very low risk & \\
\hline $50<$ RPN $<=150$ & Low risk & \\
\hline $150<$ RPN $<=200$ & Medium risk & \\
\hline $200<$ RPN $<=300$ & High risk & \\
\hline RPN $>300$ & Very high risk & \\
\hline
\end{tabular}

Table 19. Risks range 


\begin{tabular}{|c|c|c|c|c|c|c|}
\hline Failure & RCF & RPN $_{\text {RCF }}$ & ICF & RPN $_{\text {ICF }}$ & Traditional Fmea RPN & Comp-Fmea RPN \\
\hline F1 & 5 & 175 & 1 & 35 & 192 & 175 \\
\hline F2 & 1 & 100 & 3 & 300 & 320 & 300 \\
\hline F3 & 5 & 245 & 4 & 196 & 320 & 245 \\
\hline F4 & 4 & 148 & 1 & 37 & 126 & 148 \\
\hline F5 & 4 & 36 & 4 & 36 & 112 & 36 \\
\hline F6 & 5 & 85 & 3 & 51 & 192 & 85 \\
\hline F15 & 2 & 168 & 1 & 84 & 20 & 168 \\
\hline F16 & 2 & 148 & 1 & 74 & 20 & 148 \\
\hline F17 & 1 & 175 & 2 & 350 & 126 & 350 \\
\hline
\end{tabular}




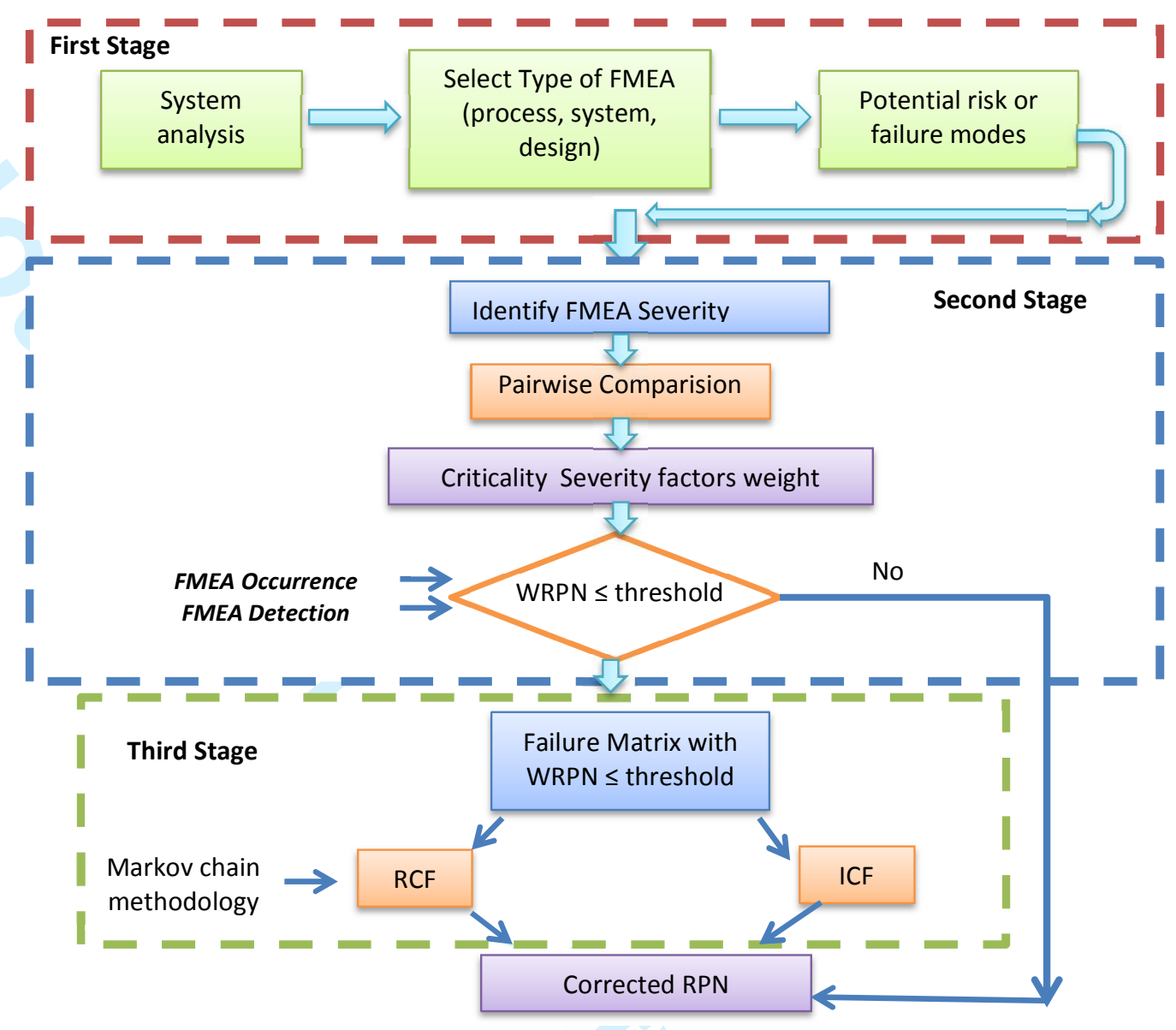

Figure 2: Research framework 

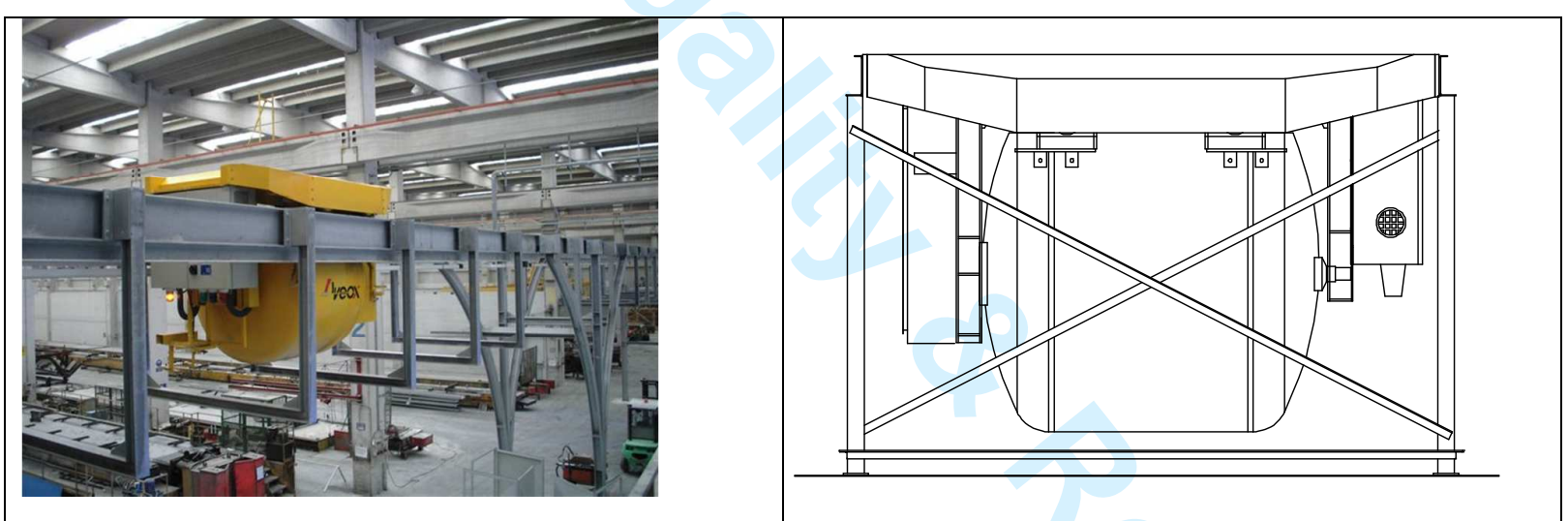

Figure 4a-4b. Aerial cart system 
Figure 5. ORU MS 3000/2000 